\title{
Implicações do tempo em filas na capacidade de carga e na satisfação dos visitantes de parques temáticos
}

Ana Carolina Padua Machado Heros Augusto Santos Lobo ${ }^{b}$

\section{Resumo}

Os parques temáticos são estruturas de lazer criadas a partir do uso da tecnologia e baseada em temas específicos, desenvolvidas para atrair grandes contingentes de pessoas em um espaço relativamente restrito. São compostos por serviços aos visitantes como estacionamento e bilheteria, além de sua finalidade maior, que são suas atrações. A lógica de funcionamento destes parques leva à formação de filas em diversos momentos da visitação. Neste contexto, a presente pesquisa teve por objetivo desenvolver um panorama sobre a percepção dos visitantes dos parques temáticos acerca do tempo de espera nas filas dos principais serviços oferecidos nestes estabelecimentos. Para tanto, foram aplicados questionários pré-estruturados para preenchimento online, com pessoas que já frequentaram parques temáticos. Os dados coletados foram descritos com apoio estatístico - regressão linear e matriz de correlação de similaridade - bem como analisados e relacionados com conceitos de satisfação na visitação, capacidade de carga social e qualidade da experiência. Os resultados demonstraram que os tempos de espera nas filas não afetaram de forma significativa a percepção dos respondentes, uma vez que as avaliações no questionário foram em sua maioria positivas. Assim, concluise que o tempo de espera em filas não afeta negativamente a percepção de lotação e a capacidade de carga social dos parques temáticos na percepção dos visitantes brasileiros. Palavras-chave: Capacidade de carga social; Percepção de lotação; Turismo de experiência.

\begin{abstract}
Implications of queuing time on the carrying capacity and satisfaction of theme park visitors

The theme parks are leisure structures created from the use of technology and based on specific themes, - designed to attract large contingents of people in a relatively restricted space. They consist of services to visitors such as parking and ticket office, including their biggest finality, which are the attractions. The logic of these parks' functioning leads to the formation of queuing at various moments of the visitation. In this context, this research aimed to develop a panorama about the perception of the theme parks' visitors about the waiting time in the queuing of the main services offered in these establishments. To do that, prestructured questionnaires were applied to be completed online, with people who already attended theme parks. The collected data were described with statistical support - linear regression and correlation matrix of similarity - as well as analyzed and related to concepts of
\end{abstract}

a. Mestrado em Turismo na Universidade de São Paulo, São Paulo, SP, Brasil. E-mail: anacarolinapadua@ usp.br

b. Doutorado em Geociências e Meio Ambiente na Universidade Estadual Paulista Júlio de Mesquita Filho, Rio Claro, SP, Brasil. Docente no Bacharelado em Turismo na Universidade Federal de São Carlos, Sorocaba, SP, Brasil. E-mail: heroslobo@hotmail.com 
satisfaction on visitation, social carrying capacity and experience quality. The results showed that the waiting times in the queues did not affect significantly the respondents' perception, since the evaluations in the questionnaire were mostly positive. It can be concluded that the waiting time in queues does not affect negatively the perception of crowd and the social carrying capacity of the theme parks in the perception of Brazilian visitors.

Keywords: Social carrying capacity; Crowded perception; Tourism of Experience.

\section{Resumen}

Implicaciones del tiempo de espera en filas en la capacidad de carga y en la satisfacción de visitantes de parques temáticos

Los parques temáticos son estructuras de ocio creadas a partir del uso de tecnología y basadas en tema específicos, desarrolladas para atraer a un gran número de personas en un espacio relativamente limitado. Se compone de servicios para visitantes, como estacionamiento y taquilla, además de su propósito principal, que son sus atracciones. La lógica de funcionamiento de estos parques lleva a la formación de filas en diversos momentos de la visita. En este contexto, la presente investigación tuvo por objetivo desarrollar un panorama sobre la percepción de los visitantes de los parques temáticos acerca del tiempo de espera en las filas de los principales servicios ofrecidos en estos establecimientos. Para ello, se aplicaron cuestionarios pre-estructurados para relleno online, con personas que ya han asistido a parques temáticos. Los datos recogidos se describieron con apoyo estadístico - regresión lineal y matriz de correlación de similitud - así como analizados y relacionados con conceptos de satisfacción en la visitación, capacidad de carga social y calidad de la experiencia. Los resultados demostraron que los tiempos de espera en las filas no afectaron significativamente la percepción de los encuestados, ya que las evaluaciones en el cuestionario fueron en su mayoría positivas. Así, se concluye que el tiempo de espera en filas no afecta negativamente la percepción de multitud y la capacidad de carga social de los parques temáticos en la percepción de los visitantes brasileños.

Palabras clave: Capacidad de carga social; Percepción de multitud; Turismo de experiencia.

\section{INTRODUÇÃo}

No contexto da sociedade contemporânea, a qual traz consigo grandes aglomerações urbanas e problemas ambientais e sociais, o lazer se configura como uma prática necessária, na medida em que representa oportunidade de diversão, desenvolvimento, descanso e fuga do cotidiano. 0 lazer proporciona maior nível de liberdade de escolha do que as atividades cotidianas e, durante sua prática, há possibilidade de exercício de criatividades e ações desinteressadas e prazerosas (Martins, 2016; Camargo, 2010). O lazer se pauta na existência de uma vida cotidiana atribulada e alienada ao trabalho, sendo oposta pelo ócio, tempo disponível, descanso e folga (Dumazedier, 2000) e funcionando como verdadeira válvula de escape dentro da lógica trabalho-moradia da sociedade contemporânea (Krippendorf, 2009). Marcellino (2007) compreende o lazer como a atividade - prática ou mental - que, desempenhada no tempo disponível, possui caráter desinteressado e se justifica pela simples busca de satisfação. Neste escopo, os parques temáticos podem ser contextualizados na lógica pós-moderna de uso do tempo livre, enquanto verdadeiros espaços de lazer e turismo, ilustrando manifestações do entretenimento contemporâneo (Ashton, 2003). 
Os parques temáticos configuraram-se ao longo do tempo como uma das atividades de entretenimento e turismo mais populares em todo o mundo. A indústria dos parques temáticos tornou-se global, cuja popularidade cresceu de maneira considerável, nas últimas décadas (Milman, 2009; Pikkemaat \& Schuckert, 2007). Os parques temáticos, cujos precursores são os "jardins dos prazeres" (Alcobia, 2004) da Europa, incrementaram-se como verdadeiras indústrias a partir do final no século XIX, nos Estados Unidos, principalmente devido ao advento do transporte aéreo, com principal expoente os complexos de parques Walt Disney World (Ashton, 2003). Com isso, passaram a desempenhar extrema importância para a atividade turística. Ainda dentro deste contexto, os parques temáticos atendem às novas demandas de lazer e às tendências do mercado turístico (Santil, 2004), já que são dinâmicos e oferecem inúmeras opções para o cenário atual de demanda diversificada e de necessidades e interesses singulares.

Diversos autores (Alegre \& Cladera, 2009; Santos, 2013; Silva \& Marques Júnior, 2017) comentam acerca da necessidade de se conhecer o perfil e o grau de satisfação de visitantes em sítios e atrativos turísticos, bem como a seus desejos de retorno, possíveis recomendações e a qualidade dos serviços oferecidos. Carmello (2002) particulariza esta análise para um exemplo em parque temático, ressaltando a importância de se conhecer a percepção dos usuários também em relação à funcionalidade e manutenção das atrações. A autora ressalta a relevância de áreas consideradas problemáticas serem diagnosticadas e corrigidas, além da necessidade de se levar em conta minuciosos detalhes relativos à dinâmica organizacional dos parques temáticos.

Embora o país possua grande quantidade de parques temáticos, proporcionalmente poucas pesquisas nas áreas de turismo e lazer são feitas sobre estes atrativos. Neste cenário, desenvolveu-se um estudo que partiu da indagação a respeito de como e em quais medidas os tempos de espera nas filas dos equipamentos podem influenciar na satisfação e experiência dos visitantes de parques temáticos ao redor do mundo.

O objetivo geral da pesquisa foi de expor um panorama sobre o grau de satisfação, expectativas, necessidades e gargalos para os visitantes de parques temáticos. Como procedimentos metodológicos, foram aplicados questionários online para obtenção de dados primários, os quais foram analisados de forma descritiva e estatística, com uso de matriz de correlação de similaridade e regressão linear, buscando explicar as correlações entre algumas das variáveis obtidas.

\section{FUNDAMENTAÇÃo TEÓRICA}

Segundo indícios históricos, pesquisas apontam que os "jardins do prazer" foram os primeiros percussores do que hoje se conhece como parques temáticos. Tais jardins surgiram em meados dos anos de 1400 e 1500, na Europa Medieval, assemelhando-se às características temáticas, ao apresentarem oferta de entretenimento, fogos de artifícios, espetáculos, jogos, ambientação e brinquedos, tanto para crianças quanto para adultos. Em meados do século XVIII, a maioria destes parques teve suas atividades encerradas, por problemas ligados às instabilidades políticas de sua época (Alcobia, 2004; Ashton, 2003; Trigo, 2010). 
Indícios de como se configuram os parques temáticos atuais começaram a surgir nos Estados Unidos, no final do século XIX, dentro do contexto da industrialização e reurbanização, aliado com o final da guerra civil americana e com o advento do transporte público. Um destaque na história mundial dos parques temáticos foi o surgimento, em 1955, do Walt Disney World (Abreu, 2008; Ashton, 2003). Através de todo o conjunto de parques temáticos pertencentes ao complexo Disney, criou-se uma grande potência turística, presente entre as cinco mais populares do mundo, atraindo mais de 30 milhões de turistas anualmente (Secall, 2006).

Dentre as principais características dos parques temáticos na atualidade está o fato de que utilizam de um tema específico para inspiração de suas atrações e ambientes físicos. Os parques temáticos oferecem experiências não-convencionais, na medida em que apresentam uma fuga do cotidiano e novas práticas sensoriais (Abreu, 2008). Também, através do uso da tecnologia, os parques temáticos a partir de um tema, constroem um ambiente formado por novas realidades ou sensações. Como uma nova cidade, este espaço desempenha função similar a de um palco e até mesmo os serviços, compras e alimentação entram nesta atuação. Desta forma, não existem limites para o rumo da imaginação de seus usuários, explorando-se, portanto, a hiper-realidade (Gastal \& Castrogiovanni, 2003).

A partir da pós-modernidade, os parques temáticos podem ser entendidos como uma de suas representações no âmbito do entretenimento. A temática específica de um parque temático é atendida por todos os seus componentes, sejam serviços, arquitetura, equipe, cenário e ambiente. Geralmente, existem certas características consideradas essenciais no que condizem ao entendimento de um parque temático: cobrança de um ingresso único para o ingresso no estabelecimento; oferta de diversão, sensações físicas e aprendizados; constituição de um verdadeiro destino independente (Ashton, 2003).

No que se refere ao panorama atual dos parques temáticos no mundo, de acordo com o último Theme Index 2016, um relatório de indicadores econômicos e de visitação nos parques temáticos, dentro do contexto dos 25 parques mais visitados mundialmente, houve um declínio de 1,1\% do número de visitação em relação ao ano de 2015 (Tea/Aecom, 2016, 2017). Já o portal TripAdvisor realizou uma pesquisa com visitantes deste tipo de atrativo, gerando um ranking dos melhores parques de diversão do mundo, eleitos em 2017. Dos 25 parques listados, 14 são dos Estados Unidos; 8 estão localizados na Europa, 2 na Ásia e 1 deles no Brasil - do um total de 53 parques temáticos cadastrados no CADASTUR (Nascimento, 2017).

Os parques temáticos são espaços provedores de serviços aos seus visitantes. Por sua vez, a satisfação dos visitantes possui relação direta com a qualidade do serviço oferecido (Carmello, 2002). A percepção de qualidade no turismo perpassa pelo fato de que os consumidores dos serviços fazem parte do processo de produção do que consomem, sobretudo em tempos atuais. Segundo Barreto, Nóbrega e Souza (2017, p. 57), o tipo de serviço ofertado é o maior diferencial percebido por um cliente e a sua estratégia está voltada "as percepções do valor percebido e se o cliente observa este valor através da qualidade dos serviços recebidos sobre os fatores pessoais e situacionais".

Como afirmam De Farias e Santos (2000), a satisfação dos consumidores está diretamente relacionada ao sucesso das organizações, à fidelidade e ao desejo de retorno. 0 grau de satisfação dos clientes possui papel essencial na gestão de 
serviços na medida em que está estritamente conectado à retenção e fidelidade dos consumidores e, por consequência, à capacidade de lucro de determinada organização. Neste sentido, segundo Toni et al. (2011, p. 95), a satisfação "é o resultado do julgamento de quão bem um produto ou serviço supriu ou está suprindo as suas expectativas. Os clientes avaliam a satisfação pela comparação entre as expectativas e as percepções".

Ainda, o grau de satisfação dos clientes é diretamente proporcional à expectativa anterior e à percepção posterior ao consumo dos clientes, na medida em que, caso a expectativa seja superada, o grau de satisfação será positivo e garantirá uma percepção satisfatória, assim como a chance de novas compras (Corrêa \& Caon, 2002). Neste contexto, a satisfação dos clientes depende exclusivamente de suas percepções acerca da qualidade dos serviços oferecidos e de suas expectativas (Bendit, 2011).

No que condiz ao grau de satisfação dos visitantes de parques temáticos, considera-se que a percepção do tempo na espera das filas dos equipamentos presentes é um dos principais fatores determinantes para definir a qualidade dos produtos e serviços desempenhados (Iglesias, 2007). Desta forma, a percepção dos usuários é afetada pelas filas de espera (de forma negativa ou positiva), e, neste sentido, segundo Fernandes (2012, p.18), "pesquisas realizadas indicaram a existência de uma relação negativa entre longos tempos de espera e a satisfação dos consumidores".

O tempo de espera nas filas em parques temáticos e outros equipamentos que oferecem serviços pode se configurar em um problema quando geridas de forma não criativa. Isso se explica pelo fato de as filas serem indicativos da velocidade da prestação do serviço, o qual representa um importante critério que revela a percepção dos clientes acerca da qualidade dos serviços oferecidos (Carmello, 2002). Segundo Stone (2012), autor do artigo "Why waiting is a torture" publicado no Jornal The New York Times, a experiência em filas de espera tem extrema influência da percepção da distância imposta até o objetivo desta espera. A sensação da espera é mais percebida do que o tempo real gasto neste processo, sendo importante, portanto, que os gestores tenham conhecimento deste fato a fim de refletirem acerca de melhores alternativas para reduzir e atenuar as sensações de espera de seus clientes (Fernandes, 2012).

Na medida em que o grau de satisfação dos clientes está diretamente relacionado à intensidade de uso de determinado local, e, além disso, a qualidade da experiência vivenciada se liga ao nível de saturação de certo recurso, surge a importância de se discutir e relacionar o conceito de capacidade de carga social neste contexto. Primeiramente, entende-se por capacidade de carga como o nível de uso que uma área pode suportar sem afetar a sua integridade (Pires, 2005). Neste sentido, a capacidade de carga é uma ferramenta que determina o limite de atividades que determinado local pode abrigar sem prejuízos. No Turismo, Ruschmann, Paloucci e Maciel (2008) afirmam que os estudos de capacidade de carga devem contribuir para a obtenção de um parâmetro inicial para a visitação, bem como formas para monitorar este número e corrigi-lo conforme necessário. 0 conceito de capacidade de carga se desdobra em diferentes perspectivas, dentre elas a capacidade de carga social.

A capacidade de carga social possui como princípio a relação de dependência entre o nível de saturação de determinado espaço com a qualidade da 
experiência vivenciada. Supõe-se, portanto, que o grau de satisfação dos usuários de determinado espaço é diretamente proporcional ao seu nível de uso (Pires, 2005). Basicamente, a capacidade de carga social destaca-se no que se refere aos impactos recorrentes da atividade turística no cotidiano econômico e social do contexto em que se está exercendo tais ações (Coccossis \& Mexa, 2004).

A noção de capacidade de carga social é também utilizada para analisar o conceito de percepção de lotação e seus impactos no grau de satisfação de turistas e visitantes. Desta maneira fatores como gestão do local em questão, comportamento dos visitantes e comunidade receptora, valores e características locais e fatores sociais e psicológicos do visitante, podem influenciar na percepção de lotação e, por consequência, na satisfação pessoal de cada um. Daí seu caráter subjetivo e dependente de julgamentos pessoais e de fatores exógenos (Coccossis \& Mexa, 2004).

\section{MÉtOdOS E ETAPAS DA PESQUISA}

A pesquisa foi realizada em quatro etapas metodológicas principais: revisão bibliográfica; procedimentos de elaboração do questionário e coleta de dados; tabulação e preparação dos dados coletados; e procedimento de análise dos dados.

A pesquisa bibliográfica inicial foi a fase exploratória da pesquisa realizada, na qual se buscou caracterizar os parâmetros mais relevantes para balizar a coleta de dados sobre temas como o grau de satisfação e perfil dos visitantes, tempo de espera nas filas das atrações de um parque temático, qualidade percebida e satisfação pela experiência vivenciada. Esta fase foi fundamental para a construção do questionário estruturado não-disfarçado (Carnevalli \& Miguel, 2001) utilizado para a coleta de dados primários, o qual foi dividido em duas partes principais: um bloco de questões sobre a experiência dos visitantes nos parques temáticos e suas respectivas escolhas e outro com o objetivo de traçar um perfil básico do respondente. Antes de sua aplicação aberta ao público, o questionário foi testado em um grupo controlado e ajustes textuais e estruturais foram realizados, para melhorar a compreensão. 0 questionário foi amplamente divulgado por meio de redes sociais, mailing eletrônico e em grupos de e-mails de pesquisadores e estudantes de lazer e turismo.

0 questionário foi disponibilizado para respostas entre os dias 28 de março e 2 de maio de 2015 - com obtenção de uma amostragem inicial, na qual foram feitas análises prévias de suficiência amostral por meio da assíntota de variáveis chave - e reaberto para novas coletas entre os dias 18 e 30 de setembro de 2015. Ao todo, foram 401 questionários respondidos. As respostas foram tabuladas no programa Excel do pacote Office, no qual foram utilizadas ferramentas de filtragem e contagem para tratamento e organização dos dados coletados.

As análises dos dados incluíram estatística descritiva básica - com evidenciação de padrões e extremos por meio de médias, máximas e mínimas - e descrições e modelagens por meio da relação entre variáveis, a qual foi feita com o uso do aplicativo XLSTAT - Pro 7.5. Neste, foram processadas matrizes de correlação e similaridade entre as variáveis e regressão linear. A matriz de correlação indicou 
o grau de similaridade e dependência estatística de cada atributo do questionário em relação aos outros, utilizando de uma escala de -1 (fraco) até 1 (forte). Como base para a análise foi utilizado o coeficiente de correlação de Pearson. A modelagem de dados da regressão linear foi feita por meio do critério $\mathrm{R}^{2}$, com método de seleção stepwise. A regressão linear indica quais variáveis possuem relação de dependência e independência com determinada variável principal. Desta forma, foram gerados gráficos e tabelas que indicaram se determinado atributo pôde ser influenciado em termos de variação por outros e vice-versa. Isso permite observar a relação existente entre as diversas variáveis presentes no questionário e as possibilidades de reflexão em termos de similaridade e influência entre estas, estabelecendo afirmações pautadas pela estatística e auxiliando, também, as análises realizadas.

Destacam-se também os principais autores que influenciaram teoricamente as análises dos dados, tais como Iglesias (2007), que discorre sobre a influência do tempo de espera nas filas sobre a experiência final do visitante; Pikkemaat e Schuckert (2007) que destacam a influência da experiência para a percepção dos consumidores; Ahmadi (1997) que parte do princípio de que as necessidades e expectativas dos visitantes não são uniformes; e Pine e Gilmore (2011), que ao se referirem ao conceito das experiências vivenciadas - um dos principais aspectos explorados na pesquisa -, qualificam-nas sobre sua importância em serem memoráveis para quem delas desfruta.

\section{RESULTADOS E DISCUSSÃo}

Do total de respostas obtidas, 111 foram para parques temáticos na América do Norte, 270 na América do Sul, 13 na Europa, 1 na Ásia e 2 resultados anulados, totalizando 397 respondentes. Aproximadamente $72 \%$ dos respondentes foram do sexo feminino e $28 \%$ masculino. Quanto ao estado civil, aproximadamente $76 \%$ dos respondentes eram solteiros, seguidos pelas pessoas casadas (21\%). Quanto à faixa etária, houve predomínio de respondentes entre 15 a 24 anos (59,2\% da amostra), seguidos daqueles entre 25 a 34 anos, com 19,6\%. As pessoas respondentes entre 15 e 34 englobaram 78,8\% da amostra, corroborando o que afirma Connellan (1998), de que os parques temáticos não são direcionados somente para as crianças. Este aspecto também foi ressaltado pelo Respondente 117: "É um mundo à parte, encantador não só para crianças! E cada vez que você vai é diferente e cada época do ano é decorado de uma forma! Nunca será igual mesmo indo várias vezes!”.

Quanto à renda mensal dos respondentes, o resultado se mostrou equilibrado entre as faixas “R\$4.430,01 a $R$ \$ 8.696,00" (22\% da amostra), seguido de "a partir de $\mathrm{R} \$ 8.696,01$ " (17,4\% da amostra) e de “R \$ 1.450,01 a R \$ 2.410,00" $(16,9 \%$ dos respondentes). Em comparação com demais variáveis sócio-demográficas, a renda foi a que apresentou resultados distribuídos de maneira mais homogênea. A importância destas variáveis em relação àquelas pesquisadas sobre o tema de qualidade da visitação e tempo em filas foi aferida pelo coeficiente de regressão linear $\left(\mathrm{R}^{2}\right)$, cujos resultados são expostos na Tabela 1. 
Tabela 1 - Coeficientes de regressão linear $\left(R^{2}\right)$ entre as variáveis sócio-demográficas e as variáveis pesquisadas

\begin{tabular}{|l|l|l|}
\hline Variável sócio-demográficas & $\begin{array}{l}\text { Variável com significância } \\
\text { estatística (regressão linear) }\end{array}$ & Coeficiente $\mathbf{R}^{\mathbf{2}}$ \\
\hline \multirow{2}{*}{ Sexo } & Permanência (t) & 0,075 \\
\hline & Frequência de visita & 0,062 \\
\hline & Filas das atrações (t) & 0,048 \\
\hline Estado civil & Filas da bilheteria (t) & 0,024 \\
\hline \multirow{2}{*}{ Faixa etária } & Avaliação geral & 0,008 \\
\hline \multirow{2}{*}{ Renda mensal } & Total de atrações & 0,053 \\
\hline & Filas das atrações (t) & 0,027 \\
\hline & Permanência (t) & 0,024 \\
\hline & Filas das atrações (t) & 0,011 \\
\hline
\end{tabular}

Nota. t=tempo.

Conforme dados da Tabela 1, destacam-se as variáveis "tempo de espera nas filas das atrações" e "tempo de permanência no parque temático" em termos de repetições em relação às variáveis sócio-demográficas. Ou seja, em termos de governança do modelo de predição da demanda dos parques temáticos em função dos resultados encontrados, estas duas são assinaladas como predominantes e focos de interesse para posteriores análises.

Quanto ao hábito de consumo em relação ao produto "parque temático", 61,5\% dos respondentes afirmaram ir raramente a estes atrativos, seguidos daqueles que vão em média 1 vez por ano $(25,7 \%), 1$ vez por semestre $(6,3 \%)$ e que foram uma única vez (6\%). Ainda, 0,5\% dos respondentes afirmaram ir mensalmente a parques temáticos. Esta constatação está em acordo com a colocação de Marcelo Cardoso, superintendente do Parque Temático Hopi Hari - Vinhedo/SP, que afirma que no Brasil, ainda não há a cultura de visitar parques (Cardoso, 2000 como citado em Carmello, 2002, p. 62). No entanto, cabe ressaltar que a frequência de visitação a parques temáticos no Brasil registrou, em 2016, crescimento de 18\% em relação ao ano anterior (Ministério do Turismo [MTUR], 2016).

Outro resultado obtido na pesquisa foi sobre a relação da experiência vivenciada nos parques temáticos e seu respectivo grau de satisfação. Neste contexto, foi dada especial atenção às filas e ao tempo de espera que os visitantes gastam nelas. Os respondentes avaliaram o tempo de espera nas filas dos estacionamentos, das bilheterias, equipamentos de lazer, equipamentos de alimentação e entradas dos parques (Figura 1).

Primeiramente, observa-se na Figura 1 a ausência significativa de uso nos itens estacionamento $(28,2 \%)$ e bilheteria $(46,3 \%)$. 0 primeiro, possivelmente em função de opções de uso de transporte público, terceirizado ou excursões fechadas para o acesso ao parque. 0 segundo, sobretudo em função da compra antecipada dos ingressos, em agências, pontos de venda ou canais remotos de venda.

Em relação à avaliação qualitativa do tempo de espera nas filas, nota-se o predomínio de avaliações positivas para os itens questionados, com destaque para o acesso ao parque temático $(73,3 \%$ de avaliações positivas, somadas avaliações "muito bom" e "bom") e as atrações (61,5\%). No outro extremo, as maiores rejeições (soma das avaliações "ruim" e "muito ruim") foram para as filas nos 
estabelecimentos de alimentação $(23,4 \%)$ e também nas atrações $(19,4 \%)$. Este último, como também foi bastante mencionado como positivo, evidencia a existência de situações extremas, o que pode ocorrer em função de diversos fatores, como a gestão das filas, data da visita e a aquisição de passes adicionais que evitam as filas comuns das atrações.

Figura 1 - Avaliação do tempo de espera nas filas em diferentes itens da experiência de visita de um parque temático

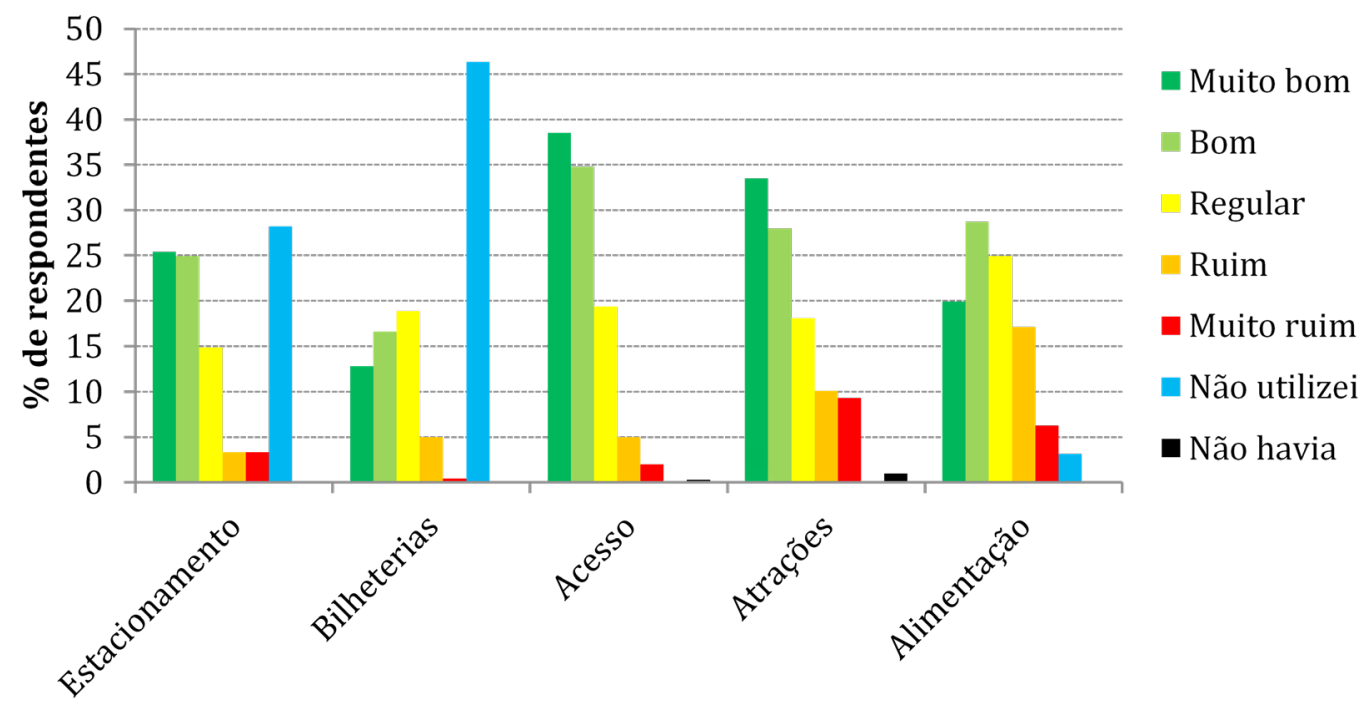

Fonte - autores

O tempo despendido nas filas também interfere na experiência geral de uso do parque temático. Em relação ao número de atrações utilizadas durante a visita, 35,3\% dos entrevistados utilizou entre quatro e sete equipamentos; $29,5 \%$ utilizaram dez ou mais; $27 \%$ utilizaram entre 7 e 10 ; e, por fim, 8,3\% utilizaram entre 1 e 4 atrações.

Neste contexto, analisando os comentários adicionais realizados pelos respondentes, os principais impeditivos mencionados para a utilização de mais atrações foram a manutenção destas e o tempo de espera nas filas. Uma interfere na outra, como assinalou o Respondente 65 no campo de comentários adicionais do formulário: "quanto maior for a quantidade de atrações em manutenção, menor será a quantidade de atrações disponíveis, o que acarreta, consequentemente, no aumento da demanda por estes e do tempo de espera nas filas". Tal situação aconteceu conforme experiência descrita pelo Respondente 51, que teve de enfrentar filas maiores por conta da grande quantidade de atrações em manutenção, justamente no período de férias escolares, a qual apresenta maior demanda e procura por equipamentos de lazer, como os parques temáticos.

Apesar das avaliações positivas no questionário, muitos dos respondentes salientaram o grande tempo de espera nas filas das atrações como prejudiciais, tanto para a qualidade da experiência e percepção final da vivência quanto para o aproveitamento dos equipamentos de lazer disponíveis. Por exemplo, como avaliações negativas neste contexto, o Respondente 103, que declarou: "foi a pior experiência que já tivemos. Pagamos muito dinheiro para aproveitar muito pouco. Acabamos desistindo dos brinquedos devido ao tempo de espera nas filas". 
Ainda, o Respondente 189 declarou que "o tempo de espera em cada atração ou brinquedo foi elevada o que repercutiu na baixa motivação para experienciar outras atrações". Tais fatos ressaltam a afirmação de Iglesias e Günther (2009), sobre a relevância do tempo de espera nas filas como um dos principais fatores de avaliação da qualidade do serviço ofertado ao cliente.

Por outro lado, existe um viés positivo nas filas, segundo relatam alguns participantes. 0 Respondente 91 registrou que "na segunda experiência o parque estava praticamente vazio, o que acarretou em não ter filas, consegui ir em alguns brinquedos umas 15 vezes em sequência, tornou o dia bem mais divertido".

Houve também participantes que destacaram o tempo de espera nas filas como parte da experiência e oportunidades de estabelecer contatos sociais. Como afirma o Respondente 98, as longas filas de espera nas atrações não representaram problemas na medida em que a empolgação de se estar em um universo tão diferente sobressaía-se sobre elas. Além disso, recursos alternativos para minimizar os impactos das filas de espera foram destacados como satisfatórios, salientando ferramentas como o "fast pass" (ingresso adquirido através de compra antecipada para não se enfrentar filas), atrações/distrações durante a espera para a utilização dos equipamentos de lazer e a realização de eventos coincidentes com a rotina de atrações dos parques (como a "noite do terror", destacada pelo Respondente 25). Portanto, através destes fatos, constata-se válida a afirmação de Pimenta (2003) sobre a importância dos gestores acerca das alternativas e inovações para minimizar o efeito das filas de espera. A continuidade da análise foi feita de forma a verificar se existiam correlações estatísticas entre as variáveis pesquisadas, conforme Tabela 2.

Em relação ao tempo despendido em filas, nota-se pelos dados da Tabela 2 uma significância estatística na correlação entre o tempo nas filas das atrações com: filas de acesso ao parque $(0,377)$; estabelecimentos de alimentação $(0,447)$; e total de atrações frequentadas $(0,354)$. Esta análise é importante, pois o foco maior da visita de um parque temático é a possibilidade de usufruir de suas atrações. Assim, vislumbram-se gargalos operacionais que são fatores intervenientes na qualidade da experiência vivenciada e na capacidade de carga social de um parque temático. De um modo geral, o tempo despendido em filas é um tempo em que não se consegue usufruir do objetivo central de se ir ao parque temático. Ao que os dados indicam, este problema é mais evidente quando se relaciona o tempo nas filas das atrações com as filas de alimentação. Ambas interferem no total de atrações utilizadas.

Embora não se tenha buscado particularizar ou mesmo comparar a realidade dos parques temáticos brasileiros com os estrangeiros, notou-se que, entre outros fatores, a localização dos parques atingiu significância estatística em relação à avaliação geral, com coeficiente 0,321 . No entanto, as variáveis que mais pesaram na avaliação geral da experiência em um parque temático foram as filas para alimentação $(0,511)$, o total de atrações visitadas $(0,540)$ e, por fim, as filas de espera nas atrações $(0,566)$. A partir destes resultados, percebe-se que a maioria das variáveis destacadas faz referência ao tempo de espera em filas ou ao consequente tempo de permanência no parque. Estes dados repetem o observado na análise de regressão linear (Tabela 1), na qual o tempo de espera nas atrações e o tempo total de permanência no parque temático atingiram as maiores repetições de significância entre as diversas variáveis analisadas. 


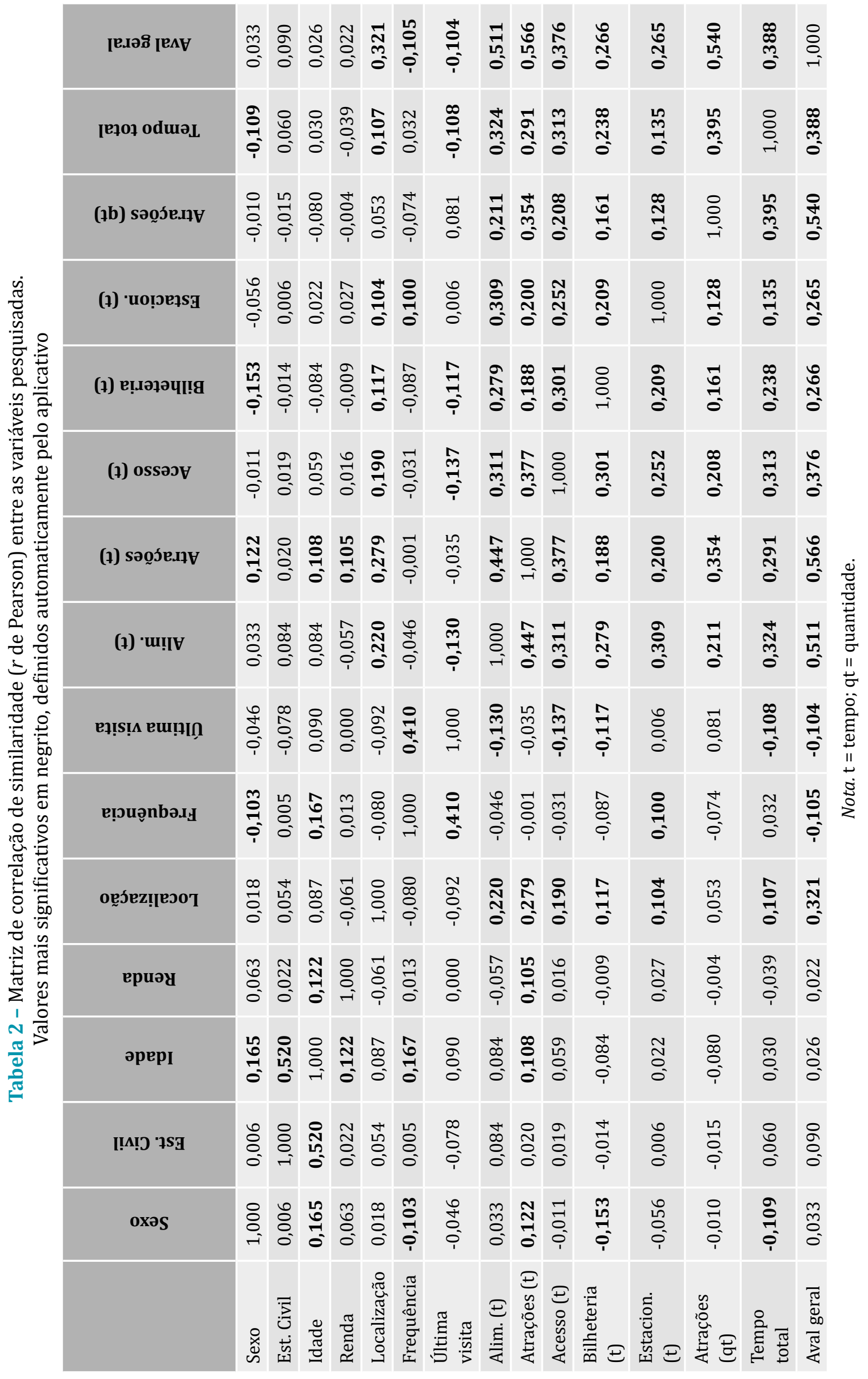


Desta forma, uma vez que a variável "avaliação geral da experiência vivenciada" faz menção à satisfação dos visitantes, ressalta-se a estreita relação entre a satisfação dos consumidores, suas experiências vivenciadas e o efeito da capacidade de carga social sobre estas, tal como exposto nos estudos de Ruschmann et al. (2008), Pires (2005) e Zacarias (2013).

Mesmo com a importância assinalada para as questões temporais e sua intervenção na experiência de visitação de um parque temático, os respondentes definiram a experiência de visitação como positiva, de um modo geral (Figura 2).

Figura 2 - Avaliação qualitativa geral da experiência vivenciada

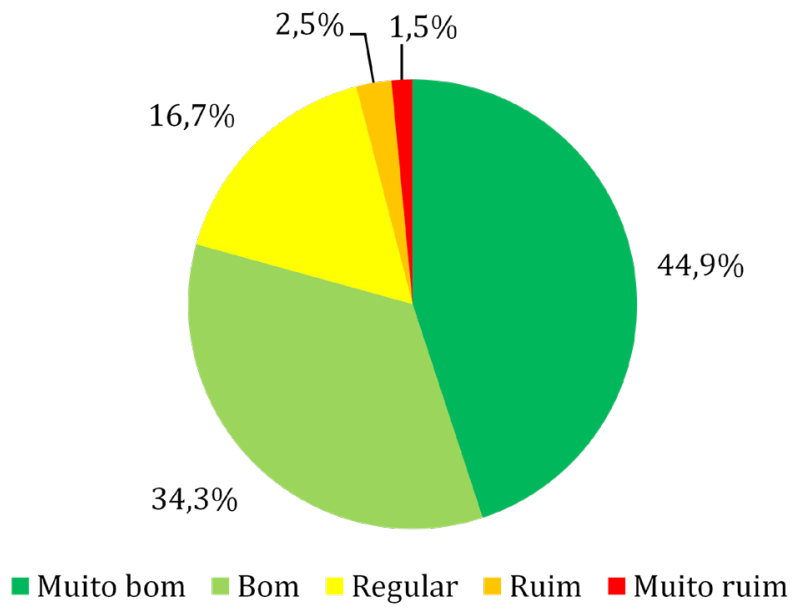

Fonte: autores

Conforme dados da Figura 2, as avaliações positivas corresponderam a 79\% das respostas (soma das opções "muito bom" e "bom"), enquanto as avaliações negativas (soma das opções "ruim" e "muito ruim") somaram apenas 4\%. Desta maneira, pode-se concluir que, apesar da presença de comentários negativos registrando acontecimentos que impactaram na experiência vivenciada dos respondentes, bem como os coeficientes estatísticos apresentados, a maioria da amostra reunida exerceu uma avaliação positiva das vivências relatadas. A exploração da temática e de recursos variados para transmitir a essência do tema e conduzir o visitante no universo criado foi uma das observações mais ressaltadas, as quais, segundo os respondentes, foram consideradas fatores positivos e de sucesso para a concretização da experiência final. Neste sentido, resgata-se o que afirmam Pine e Gilmore (2011) sobre o poder das experiências de se tornarem memoráveis para aqueles que delas usufruíram. Além disso, o atendimento foi um fator muito levado em consideração pelos respondentes, os quais relataram experiências positivas e negativas acerca deste aspecto, de forma que, em todos os casos, foi ressaltada a importância deste serviço como um dos fatores cruciais para a formação da percepção final da vivência.

\section{CONSIDERAÇÕES FINAIS}

Os Parques Temáticos, através de sua evolução histórica, configuraram-se como uma das mais interessantes opções de passeio aos turistas pelo mundo. 
Com o uso de uma temática principal, aliada com artifícios responsáveis por inserirem os usuários ao universo e fantasia propostos, estes se configuram como verdadeiros diferenciais em relação aos demais parques de diversão. Além disso, possuem relevância econômica para as localidades em que estão inseridos, além de serem importantes indicadores e movimentadores da atividade turística. Ainda, são exemplos da importância de se refletir acerca das boas práticas de gestão, uma vez que lidam com visitantes, suas expectativas e necessidades variadas. Neste contexto, ressalta-se a importância desta pesquisa na medida em que se insere na gama de estudos realizados sobre parques temáticos no mundo. Ainda, uma vez que este estudo possui grande foco no grau de satisfação dos visitantes, os resultados obtidos são também relevantes para se compreender as preferências destes atores e como estas são importantes para se refletir nas técnicas e aprimoramento da gestão dos parques temáticos e seus serviços oferecidos.

Em relação aos objetivos propostos pela pesquisa, os resultados responderam as questões levantadas, além de estabelecerem um panorama geral acerca das necessidades e grau de satisfação dos visitantes, principalmente no que se refere ao tempo de espera nas filas. Outros pontos adicionais também puderam ser identificados com o uso dos comentários opcionais do questionário, os quais agregaram informações úteis para a compreensão da percepção dos visitantes.

Quanto aos procedimentos metodológicos, em relação à aplicação de questionários estruturados e distribuídos de forma online, pode-se concluir que esta conseguiu atender de forma bem sucedida às expectativas e às demandas estipuladas nos objetivos, além de atingir uma quantidade de respostas satisfatórias para a realização da descrição e análise dos dados coletados. Neste sentido, as formas de divulgação do questionário se mostraram eficientes.

Por fim, em relação à questão inicial desta pesquisa, ou seja, o quanto o tempo de espera nas filas afeta (ou não) a percepção dos usuários dos parques temáticos, a maioria dos resultados apontou para um cenário positivo, mesmo com algumas observações negativas. Isso indica que, a percepção dos visitantes acerca do tempo de espera nas filas não foi impactada de forma geral, uma vez que a grande maioria assinalou por opções positivas sobre estes aspectos. Tal fato pode ser reforçado pela grande maioria dos respondentes classificarem suas experiências vivenciadas com a opção "Muito bom", o que mostra que a percepção final desta amostra não foi afetada pela espera ou possíveis acontecimentos negativos. Desta forma, entende-se que os visitantes de parques temáticos toleram o tempo de espera em filas e que estas não prejudicam significativamente a experiência de visitação. Com isso, conclui-se que, ao contrário do que se intui e do que a literatura afirma em alguns casos, o tempo de espera em filas não afeta negativamente a percepção de lotação e a capacidade de carga social dos parques temáticos.

\section{REFERÊNCIAS}

Abreu, E. (2008, agosto). O poder da marca Disney como atrativo turístico. Anais do Seminário da Associação Nacional de Pesquisa e Pós-Graduação em Turismo, Belo Horizonte, MG, Brasil, 5. Recuperado de https://www.anptur.org.br/anais/anais/files/5/21.pdf.

Ahmadi, R. (1997). Managing Capacity and Flow at Theme Parks. Operations Research, 45 (1), 1-13. 
Alcobia, R. (2004). Dimensões da hospitalidade nos parques temáticos (Dissertação de mestrado). Universidade Anhembi Morumbi, São Paulo, SP, Brasil.

Ashton, M. (2003). Turismo: a mutação do cotidiano. In Barreto, M. (Org.), Turismo, cultura e sociedade (pp. 11-24). Caxias do Sul: EDUCS.

Alegre, J., \& Cladera, M. (2009). Analysing the effect of satisfaction and previous visits on tourist intentions to return. European Journal of Marketing, 43(5/6), 670-686.

Barreto, M., \& Nóbrega, K., Souza, L. (2017). Estratégia de serviços: o que há de comum entre os modelos teóricos? Revista Raunp, 9(2), 57-68.

Bendit, Z. (2011). Serviços: Um mundo novo. São Paulo: GVPec.

Camargo, L. O.L. (2010). O que é lazer (4a ed.). São Paulo: Editora Brasiliense.

Carmello, M. (2002). Marketing Mix de Parques Temáticos: O caso do Parque da Mônica de São Paulo (Dissertação de mestrado). EAESP, Fundação Getúlio Vargas, São Paulo, SP, Brasil.

Carnevalli, J.A., Miguel, P. (2001, outubro). Desenvolvimento da Pesquisa de Campo, Amostra e Questionário para a Realização de um Estudo Tipo Survey sobre a Aplicação do QFD no Brasil. In XXI Encontro Nacional de Engenharia de Produção, Conference Paper. Maceió.

Coccossis, H., \& Mexa, A. (2004). The Challenge of Tourism Carrying Capacity Assessment: Theory and Practice. Reino Unido: Ashgate Publishing.

Connellan, Tom. (1998). Nos bastidores da Disney: os segredos do sucesso da mais poderosa empresa de diversões do mundo (19a ed.). São Paulo: Futura.

Corrêa, H., \& Caon, M. (2002). Gestão de serviço: lucratividade por meio de operações e satisfação dos clientes (1a ed.) São Paulo: Atlas.

De Farias, S., \& Santos, R. (2000). Modelagem de equações estruturais e satisfação do consumidor: uma investigação teórica e prática. $R A C, 4(3), 107-132$.

Dumazedier, J. (2000). Lazer e cultura popular (3a ed.). São Paulo: Perspectiva.

Fernandes, A. (2012). A Influência do Tempo de Espera na Satisfação e na Lealdade em Serviços (Dissertação de Mestrado). Universidade do Porto, Porto, Portugal.

Gastal, S., \& Castrogiovanni, A.C. (2003). Turismo na pós-modernidade (desinquietações). Porto Alegre: EDIPUCRS.

Iglesias, F. (2007). Comportamentos em filas de espera: uma abordagem multimétodos (Tese de Doutorado). Universidade de Brasília, Brasília, Brasil.

Iglesias, F., \& Günther, H. (2009). A espera na vida urbana: uma análise psicossocial das filas. Psicologia em Estudo, 14(3), 537-545.

Krippendorf, J. (2009). Sociologia do turismo. São Paulo: Aleph.

Marcellino, N. (2007). Lazer e educação (12a ed.). Campinas: Papirus.

Martins, J (2016). Lazeres e tempos livres, entre os ócios desejados e os negócios necessários. Revista do Centro de Pesquisa e Formação, 2, 51-58.

Milman, A. (2009). Evaluating the guest experience at theme parks: an empirical investigation of key attributes. International Journal of Tourism Research, 4,(11), 373-387.

Ministério do turismo (2016, julho). Cresce visitação a parques temáticos e aquáticos no Brasil [Portal do Ministério do Turismo]. Recuperado de http://www.turismo.gov. br/\%C3\%BAltimas-not\%C3\%ADcias/7086-cresce-visita\%C3\%A7\%C3\%A3o-a-parquestem $\% \mathrm{C} 3 \%$ A1ticos-e-aqu\%C3\%A1ticos-no-brasil.html.

Nascimento, L (2017, setembro). Cadastro é obrigatório também para parques temáticos [Portal do Ministério do Turismo]. Recuperado de http://www.turismo.gov.br/últimasnotícias/8200-cadastur-cadastro-é-obrigatório-também-para-parques-temáticos.html. 
Pikkemaat, B., \& Schuckert, M. (2007). Succes factors of theme parks - An exploratory study. Preliminary communication, 55(2), 197-208.

Pimenta, L. (2003). Gerenciamento das Filas de Espera. Editorial Laranjeiras, 1(2), 59 - 60.

Pine, J., \& Gilmore, J. (2011). The experience economy (2a ed.) Massachusets: Harvard Business Review Press.

Pires, P. (2005). "Capacidade de carga" como paradigma de gestão dos impactos da recreação e do turismo em áreas naturais. Revista Turismo em Análise, 16(1), 5-28.

Ruschmann, D., Paolucci, L., \& Maciel, N.A.L. (2008). Capacidade de carga no planejamento turístico: estudo de caso da Praia Brava - Itajaí frente à implantação do complexo turístico habitacional canto da brava. Revista Brasileira de Pesquisa em Turismo, 2(2), 41-63.

Santil, J. (2004). Os Parques Temáticos no contexto da atividade turística. Turismo: Visão e Ação, 3(7), 83 - 96.

Santos, G.E.O. (2013). 0 que determina a satisfação dos turistas internacionais no Brasil? Turismo em Análise, 24(3), 521-543.

Secall, R. (2006). La estrutura de los mercados de los turismos específicos (pp. 171 - 224). In Secall, R., Bernier, E., García, R., \& Rojo, M. Estructura de mercados turísticos. Barcelona: Editorial UOC.

Silva, F., \& Marques Júnior, S. (2017). Fatores que afetam o encantamento do cliente do turismo de lazer a partir da experiência em parques temáticos. Revista Turismo - Visão e Ação - Eletrônica, 19(1), 103-127.

Stone (2012, agosto). Why waiting is torture. Recuperado de https://www.nytimes. com/2012/08/19/opinion/sunday/why-waiting-in-line-is-torture.html.

Tea/Aecom (2016). Theme Index and Museum Index: The Global Attractions Attendance Report. Burbank: Themed Entertainment Association (tea). Recuperado de http://www. teaconnect.org/images/files/TEA_235_103719_170601.pdf.

Trigo, L. G. G. (2010). Turismo de Experiência. São Paulo: SENAC.

Toni, D., Larentis, F., Mattia, A., \& Milan, G. S. (2011). A imagem do comércio varejista e a satisfação dos consumidores: um estudo exploratório ambientado em uma cidade da Serra Gaúcha. BASE - Revista de Administração e Contabilidade da UNISINOS, 8(1), 91-104.

Zacarias, D. (2013). Avaliação da capacidade de carga turística para gestão de praias em Moçambique: o caso da praia do Tofo. Revista de Gestão Costeira Integrada, 13(2), 205-214.

Recebido em: 20/08/2018

Aprovado em: 28/04/2019

\section{CONTRIBUIÇÕES}

Ana Carolina Padua Machado: Definição do problema de pesquisa e objetivos, desenvolvimento da proposição teórica, realização da revisão bibliográfica e fundamentação teórica, escolha dos procedimentos metodológicos, coleta de dados e análise de dados, elaboração de tabelas, gráficos e figuras, realização de cálculos e projeções, revisão crítica do manuscrito, redação do manuscrito e adequação do manuscrito às normas da RTA.

Heros Augusto Santos Lobo: Definição do problema de pesquisa e objetivos, desenvolvimento da proposição teórica, realização da revisão bibliográfica e fundamentação teórica, escolha dos procedimentos metodológicos, coleta de dados e análise de dados, elaboração de tabelas, gráficos e figuras, realização de cálculos e projeções, revisão crítica do manuscrito e redação do manuscrito. 